\title{
Thermal-Fluids Analysis of a Hybrid Solar/Compost Waste Heat Updraft Tower
}

\author{
Kevin R. Anderson, Maryam Shafahi, and Chris McNamara
}

\begin{abstract}
This paper presents the results for a feasibility study of a solar chimney which uses low-grade waste heat from compost in conjunction with solar energy transmitted via a transparent roof top. The feasibility study shows that the solar chimney's turbine power increases with pressure ratio, the height of the chimney as well as the differential temperature in the chamber. This paper also outlines the thermodynamic modeling related to using waste heat from composting to increase the air temperature in the inlet chamber of a solar chimney. It is found that from this analysis that the average temperature in the chamber increases as a function of the chimney inlet chamber axial length. The combined raw in input total heat gain for this hybrid solar composting chimney is found to be $6.24 \mathrm{MW}$ of which $66 \%(4.12 \mathrm{MW})$ is comprised of solar, and $34 \%(2.12 \mathrm{MW})$ is comprised of composting energy
\end{abstract}

Index Terms-Composting, waste heat recovery, solar updraft tower .

\section{INTRODUCTION}

Research suggests that only $8 \%$ of our nation's supply of electricity comes from renewable energy. The remaining amount of produced power typically comes from the burning of fossil fuels and other nonrenewable sources. This opens the door for various types of renewable energy to be introduced into the power grid, coming in numerous forms such as of solar, wind, and hydroelectric. The stakeholders for the development of this renewable energy technology include the community, nation and global inhabitants. A solar updraft tower is a renewable energy structure that harvests energy from the sun and creates high velocity wind speed in its collector to run turbines. A compost pile contains microbes that digest organic material and break it down into smaller parts. When they do this, they produce heat as a byproduct. The heat production depends on the size of the compost pile, its moisture content, aeration, and $\mathrm{C} / \mathrm{N}$ ratio. A well composted mass often reaches temperatures of $66^{\circ} \mathrm{C}$ to $82^{\circ} \mathrm{C}$, which falls within the range of low-grade waste heat. Compost managers strive to keep the compost below about $65^{\circ} \mathrm{C}$ since hotter temperatures cause the beneficial microbes to die off. Aeration is typically used to manage the compost temperature The energy liberated by aeration can be fed into the

Manuscript received January 19, 2015; revised July 20, 2015. This work was supported by the COMPO Energy, Inc. which holds U.S. Green Patent $7,956,487$ on the compost solar chimney concept aspect of renewable energy presented herein.

The authors are with the Solar Thermal Alternative Renewable Energy $\mathrm{Lab}$ in the Mechanical Engineering Department, California State Polytechnic University (Cal Poly Pomona), Pomona, CA 91768 USA (e-mail: kranderson1@ csupomona.edu, chris.m.mcnamara@gmail.com). convective stream of the solar updraft tower. This paper extends this concept as a viable renewable energy source by extending the use of the solar chimney which uses low-grade waste heat from compost in conjunction with solar energy transmitted via a transparent rooftop in order to set up the convective flow in the solar updraft tower which uses turbines to harness the energy and convert the flow work into electricity. The convective air-flow in the updraft tower propels a novel concept of turbine arrays fixed in the tower of the solar tower. In this paper, the mathematical model of the system is established based on thermodynamics and elementary fluid mechanics and heat transfer theory. Various parameters including the heat source temperature, the ambient air temperature and area of heat transfer are examined to evaluate their effects on the system performance such as velocity of updraft, mass flow rate of air, tons of compost per day, compost moisture content, aeration, power output and energy conversion efficiency The variety of hybrid clean energy technologies associated with our research is illustrated in Fig. 1.

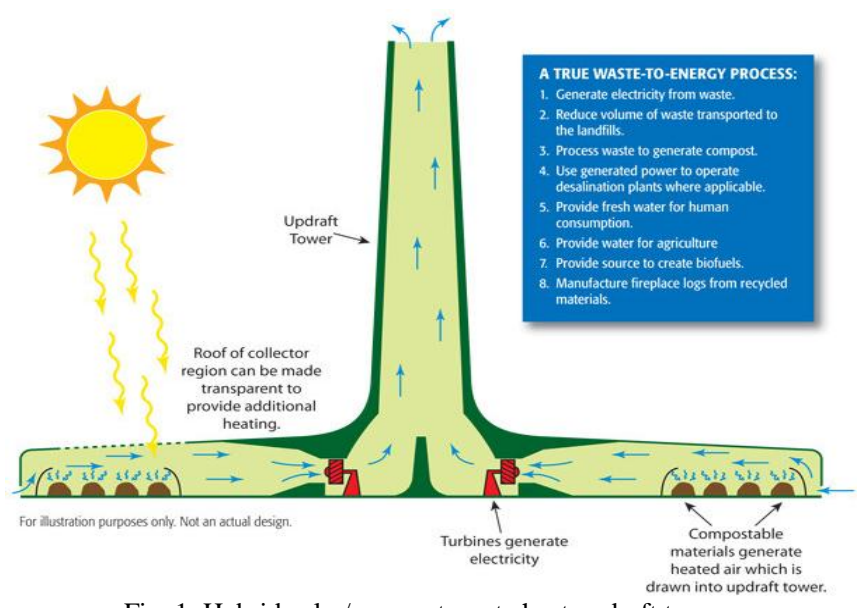

Fig. 1. Hybrid solar/compost waste heat updraft tower

A comprehensive overview of solar chimney power technology is given in [1] including a review of the associated technologies, numerous on-site case studies and economic analysis. The first prototype for a solar updraft tower was built in Manzanares, Spain in 1982 [2]. The purpose of the tower was to prove theory and calculations by performing field measurements of power output and efficiency in realistic meteorological conditions. The tower ran successfully for approximately 8 years, generating a maximum power output of roughly $50 \mathrm{~kW}$. The tower itself was 195 meters high with a diameter of 10 meters at the collection site. The collector spanned 46,000 square meters, and the tower operated 24 hours a day. The tower was eventually decommissioned in 1989 after the guy-wires succumbed to corrosion and the 
updraft tower fell. However, the scientists in charge of updraft tower were able to verify that a solar updraft tower was a viable source for renewable energy generation. Upon the success of the first solar updraft tower in Spain, many proposals and projects have been presented for construction. One project in progress will be located in La Paz, Arizona, where scientists hope the hot and arid climate will provide ideal atmospheric conditions for the updraft tower to operate. The updraft tower is being built by EnviroMission [2], a renewable energy company based in Australia who will begin construction in the summer of 2013 and hope to finish construction in 2015. The proposed solar updraft tower is expected to generate just under $200 \mathrm{MW}$ of clean energy 24 hours a day.

\section{LITERATURE REVIEW}

The concept of solar chimney of solar updraft tower as a means to generate electricity is a feasible means of renewable energy technology. Recent worldwide studies focused at the utilization of solar updraft towers for power generation include that of Schlaich et al., 2005 [2] wherein a solar thermal power plant utilizing a combination of a solar air collector and a central updraft tube to generate a solar induced convective flow which drives pressure staged turbines to generate electricity is presented. The work of [2] presents a simplified theory of the solar tower, practical experience, and economy of solar updraft towers. In the work of Al-Dabbas, 2011 [3], the first pilot demonstration of a solar updraft tower power plant in Jordan is presented. The study of [3] is motivated by the high cost of importing heavy fuel oil from neighboring countries of Jordan. The work of [3], [4] describes a systematic experimental study on the pilot solar updraft tower power plant model system with particular attention given to measurements of air velocity, temperature, solar radiation and voltage difference. In [3], the experimental data were taken from a very small pilot project in contrast to other prototypes that were constructed in the backyard facilities. For the experimental part of [5], the solar updraft power plant was a pilot project with an updraft power plant height $H=4 \mathrm{~m}$, updraft power plant radius $R=0.29 \mathrm{~m}$, a plastic solar collector area $A=36$ square meters, a collector roof height $=1 \mathrm{~m}$, and a wind turbine that was a combination of the suction fan with a diameter $D=0.5 \mathrm{~m}$, and a small generator $(6$ Volts). In the US, the recent 2014 studies of [6], [7], researchers at the University of New Mexico reported new data on solar energy whereby a novel design for a solar updraft tower, wherein the chimney that generates the updraft is a self-supporting, free-standing stack of hollow gas-filled toroidal inflatable balloon like structures is proposed. Alternative energy storage techniques using phase-change materials and a solar chimney is presented in the work of Bernardes and Zhou, 2013 [4], wherein water bags are used as sensible heat storage where it is reported that thicker water bags can reduce more efficiently the daily temperature spam and thermal stratification is an import thermal effect. In the follow on work of Bernardes and Zhou, 2013 [4], the sensible heat storage physical process in a solar updraft tower collector taking into account the transient heat transfer in some typical soils through conduction, convection and solar radiation is presented. The simulations of [8] which included thermal diffusivity of the soil, predict the thermal behavior for different soil materials revealing that materials with lower thermal diffusivity can decrease substantially output peaks for periods with greater heat gains. In the recent study of Muller 2010 [5], a low pressure solar thermal conversion device is presented. In [5] it is reported that maximum theoretical efficiencies ranged from $7 \%$ for a temperature difference of $60 \mathrm{~K}$ to $18 \%$ for a difference of $195 \mathrm{~K}$. thereby warranting the low pressure solar thermal conversion device as a viable technology for applications in solar energy conversion. In conjunction with the feasibility studies and novel design concepts outlined above, a comprehensive thermodynamic analysis of a low-temperature waster recovery system based on the concept of a solar updraft tower is given in the recent work of Chen et al. 2014 [6] whereby low-temperature waste heat is used to heat air in order to produce an air updraft in the chimney tower, subsequently the air updraft propels a turbine fixed at the base of the chimney tower to convert waste heat into electricity. For the work in [6], hot water is selected as the representative of low-temperature waste heat sources. In [6], the heat source temperature, ambient air temperature and area of heat transfer are examined to evaluate their effects on the system performance parameters including updraft velocity, mass flow rate of air, power output, and conversion efficiency. It is concluded in [6], that the velocity of air demonstrates a better stability metric as opposed to the mass flow rate of air. Also, per [6], as expected the pressure difference changes when temperature of heat source, ambient air temperature or area of heat transfer changes.

More recently [9] a model for time dependent analysis of solar chimneys is presented where the energy balance equations for three components of solar chimneys, absorbing plate, cover glass and air-gap are discretized with respect to time using an implicit finite difference model. In the work of [10] solar chimney power plants are investigated numerically showing detailed time-dependent high-resolution simulations

of the flow in the collector and chimney of the model provide detailed insight into the fluid dynamics and heat transfer mechanisms. In the work of [11], the use of solar chimneys in cogeneration applications in coal gasification is examined. The study of [12] presents a cost-benefit analysis of power generation from a commercial reinforced concrete solar chimney power plant. In [13], the geometrical shape of the solar chimney is studied where it is concluded that after a comprehensive analysis of system output power and efficiency, that the cylindrical chimney would be the best choice among the three basic configurations, whose optimum height to diameter aspect ratio. The work of [14] presents an experimental and numerical model of a solar whereby the maximum air velocity was $0.8 \mathrm{~m} / \mathrm{s}$ for a radiation intensity of $750 \mathrm{~W} / \mathrm{m}^{2}$ at an air gap of $50 \mathrm{~mm}$ thickness. In [15] a novel small scale model of solar chimney was investigated experimentally and numerically where the experimental results show that utilization of intensifiers lead to a maximum velocity of $5.12 \mathrm{~m} / \mathrm{s}$. The research of [16] presents numerical simulations of a solar chimney power plant with a radiation model wherein the results indicate that the radiation model is essential in preventing the overestimation of energy absorbed by the solar chimney power plant. In [17], a mathematical 
thermal model for steady state airflow inside a solar chimney power plant based upon the modified Bernoulli equation with buoyancy effects and ideal gas equation are given. The results show that the chimney height, the collector radius, the solar irradiance, and the turbine head are essential parameters for the design of solar chimneys. The maximum power generation depends on the turbine head and the relation is not monotonic. In the study of [18], a solar chimney pilot power plant with 3 $\mathrm{m}$ collector diameter and $2 \mathrm{~m}$ chimney height was designed and constructed. The temperature difference between the chimney inlet and ambient reached to $263{ }^{\circ} \mathrm{C}$. The maximum air velocity of $1.3 \mathrm{~m} / \mathrm{s}$ was recorded inside the chimney. In the work of [19] experiments were carried out with a solar chimney model showing that an optimum gap-to-height ratio of 0.5 maximized the airflow rate in the chimney.

The literature survey presented herein shows that research in solar updraft based renewable energy systems is active and on-going. This leads to the motivation of the current paper, which is to investigate the feasibility of using a hybrid solar chimney fed with compost waste heat in order to promote the updraft flow of air which can be harnessed for electricity. The present paper presents a feasibility study of a thermal composting updraft tower based on the concept of Compo Energy Inc. [7]. The ultimate goal of this project is to develop a prototype facility of a Solar Updraft Tower and Turbine System Utilizing Compost Waste Heat and Solar Renewable Energy. This research is currently being sponsored by a Southern California start-up company, COMPO Energy, Inc. [7] which holds U.S. Green Patent 7,956,487 on the compost solar chimney concept aspect of renewable energy presented herein. A solar updraft tower (aka solar chimney) is a renewable energy structure that harvests energy from the sun and creates high velocity wind speed in its collector in order to run turbines which generate electricity. The stakeholders for the development of this renewable energy technology include the community, nation and global inhabitants. The novelty of this current research is that it extends the concept of composting as a viable renewable energy source by the use of the solar chimney which uses low-grade waste heat from compost in conjunction with solar energy transmitted via a transparent rooftop in order to set up the convective flow in the solar updraft tower which uses turbines to harness the energy and convert the flow work into electricity. The convective air-flow in the updraft tower propels a novel concept of turbine arrays fixed in the tower of the solar tower.

\section{COMPOSt WASte Heat ReCOVERY}

The area of compost engineering is a well established field which as documented in [20]. For the baseline study of the solar chimney using compost waste heat herein, the technology of the Agrilab compost isobaric heat recovery unit is as follows [21] "Agrilab Technologies, LLC offers an innovative approach for changing waste into resources while recovering the thermal energy. The Agrilab Isobar Heat Exchange System reduces reliance on fossil fuels and supports new and sustainable approaches to accelerating the deployment of clean energy solutions for increased agricultural productivity. Compost is natural recycling - converting food scraps, leaves, manures into soil building compost and mulch. During the decomposition process, medium and large compost piles generate substantial heat. The biological process releases energy visible as steam. The Agrilab Isobar Heat Exchange System captures the steam/vapor generated during the composting process and channel it through an insulated network (see Fig. 2).

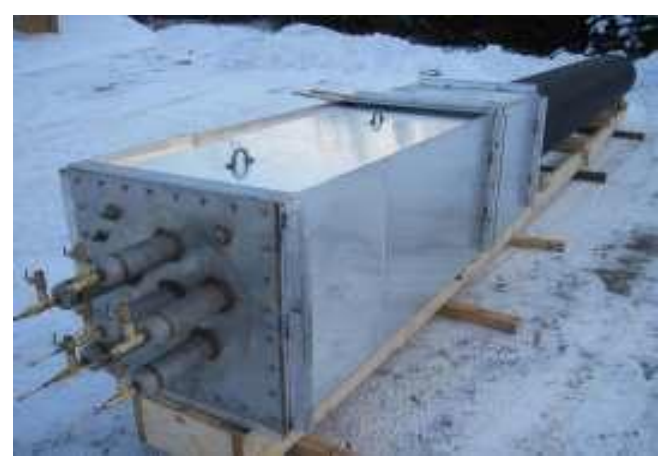

Fig. 2. Agrilab's isobaric heat recovery unit [9].

An efficient electric fan, or fans on a timer, control the vacuum of the compost vapor. It is drawn into a controlled chamber which houses 6-12 Isobar tubes - two-phase super conductors which transfer the heat from the vapor. A portion of the Isobars ${ }^{\circledR}$ are sealed into a water tank. When the water temperature in the pre-heater reaches the desired temperature, it can then be directly circulated to where it is needed. The heated water could also be transferred into larger hot water reservoirs for direct use or circulated for specific heating needs. The only moving parts are the small in-line blower fan(s) and a required circulator pump for the heated water. Both are commonly available and easily replaced if necessary. The patented Agrilab Isobar technology facilitates capturing the heat generated during the composting process. This heat can then be used for numerous applications ranging from space heating of buildings, greenhouses, aquaculture, or hot water needs. Farms, composters and waste management companies currently use propane, oil and diesel for the bulk of their energy needs. Heat capture and transfer can play a valuable role in offsetting dependence and expenses related to the use of these traditional fuels" (see Fig. 3).

The throughput is designed to accommodate 50 to 150 tons of compostable material every 2 months. Values for waste heat generation vary depending on the make-up of the waste. AgriLab Technologies LLC [21] operates under the following parameters:- $17.8{ }^{\circ} \mathrm{C}$ to $-1{ }^{\circ} \mathrm{C}$ ambient air temperature, 57 L/ton $-570 \mathrm{~L} /$ ton, $66{ }^{\circ} \mathrm{C}$ heated air temperature. The heat release in the compost is $0.516 \mathrm{~W} / \mathrm{kg}$ per the specifications of [21].

\section{HYBRID TOWER THERMAL FLUIDS ANALYSIS}

In this section of the paper we present the details of the derivation of the thermodynamic model governing the increase in the solar chimney chamber air temperature due to composting. As previously mentioned, the thermodynamic analysis for solar tower designs are fairly well documented through many sources and methods, notably [1], [2], [6], [8], [23], [24]. The portion of the proposed design herein which 
uniquely extends the concept of the solar chimney is the addition of compost waste heat as a methodology of adding energy to the air while simultaneously decomposing biological waste. Therefore the key stage of analysis in the current proposal is the modeling of the air via the bottom portion of the tower. This is because the solar and compost head additions will modify the boundary condition of the tower segment inlet air, but the analysis will remain the same throughout the tower.

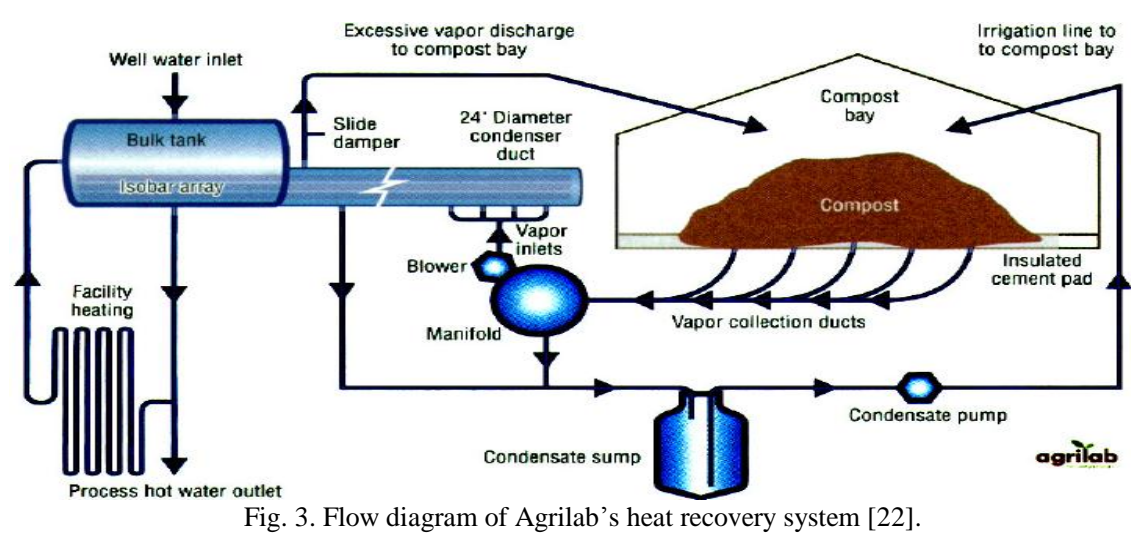

There are many variables at play in the analysis of the air as it is inducted towards the tower. The three main components are: construction geometry, biological waste heat addition, and global location. The first component to be addressed is that of geometrical considerations. COMPO Energy Inc. [7], has expressed an interest in designing a structure in which the base is divided into twelve equally structured compartments for serviceability concerns. These compartments would be serviced such that at any point in time, two will be inactive for maintenance while the remaining ten will be active and contributing to the heating of inducted air. Fig. 4 shows a plan-view of the proposed geometrical model for the base of the solar chimney:

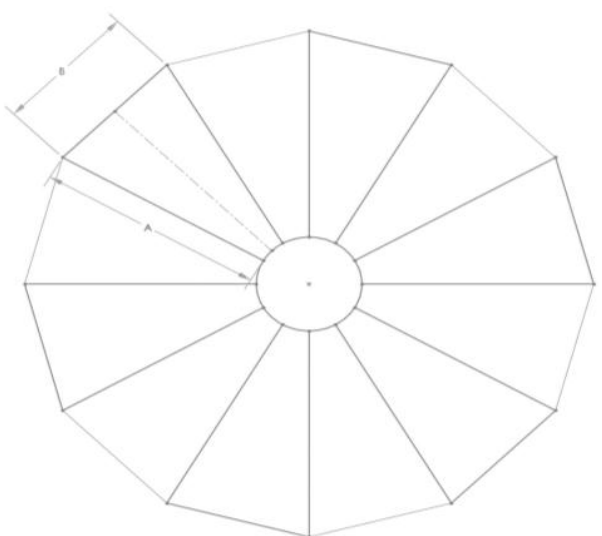

Fig. 4. Solar chimney base model (plan view).

This proposed model lends itself to easy analysis for heat transferred to the air. The first step to processing the geometry for analysis in a heat transfer model is to break down the overall geometry differentially. It will be noted that the proposed heat transfer model is analogous to that of internal pipe flow and therefore temperature will vary axially towards the tower center. This will require a geometrical definition in terms of an axial viewpoint. Examining a single chamber for the tower base, it is recognized to be an isosceles triangle since the geometry of each chamber must be equal. Using a basic calculus approach to analyze a differential area element as shown in Fig. 5 (neglecting the small area which departs from the tangent at the intersection with the tower), the following relationships in terms of the base, $B$, and height $H$, are obtained:

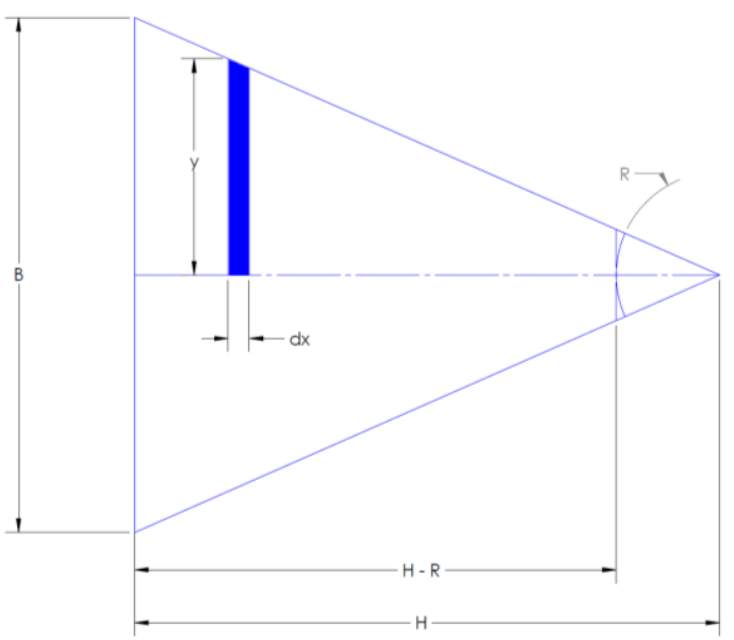

Fig. 5. Single chamber geometry model.

$$
\begin{array}{r}
y=\frac{B}{2}\left(1-\frac{x}{H}\right) \\
d A=B\left(1-\frac{x}{H}\right) d x
\end{array}
$$

Also noting that the prescribed geometry will adhere to the following relation:

$$
H=\frac{B}{2 \tan \frac{\pi}{12}}
$$

where either the base, $B$ may or axial length may be chosen to suit the design (exterior door dimensions or flow length). The cross sectional area will be an important parameter in flow calculations and is then given by:

$$
A_{c}(x)=2 y d
$$


where $d$ represents the open height of the flow above the compost pile for air flow (porous flow through the compost is not to be considered in this analysis). Considering that the geometrical properties of the flow space have been modeled, the second consideration is that of geological effects. One of the two primary drivers of air induction is that of solar heat input. Values of irradiance per location are commonly available and tabulated with excellent accuracy by agencies such as "National Solar Radiation Database" of National Renewable Energy Laboratory (NREL) [25]. This data is readily implemented in the present model. However, it should be noted that these values of irradiance are highly dependent on location and will affect the solution. Additionally, shading due to the central tower will attenuate this value of irradiance. The following equation is applicable to a differential strip of chamber area for quantifying the heat input:

$$
Q_{i r r}=\tau_{s} G d A
$$

where $d A$ is as previously defined, $G$ represents the daily annual average irradiance reported at the tower's location by NREL, $\tau$ is the transmissibility of the selected roof material and $f_{s}$ is the shading factor. Of these variables the least well known is that of the shading factor. For the present analysis, a conservative value of $60 \%$ is chosen as an estimate. Another consideration for locational properties is ambient air and earth temperatures which will change the base inlet and convective floor boundary conditions. The final consideration before progressing with the base model is that of heat input from the compost. While heat input from the solar side is fairly easy to establish or estimate, limited data is available for waste heat values of compost. As discussed earlier in the paper, using experimental data from Agrilab Technologies [9], a heat input of $0.516 \mathrm{~kW} /$ ton of waste was obtained due to composting. Additionally, compost batch surface temperature data acquired by Smith and Aber [10] show an average (yet oscillatory) surface temperature of compost batches of around $120{ }^{\circ} \mathrm{F}\left(49^{\circ} \mathrm{C}\right)$. In both considerations, the compost piles are assumed to be well maintained in order to supply energy consistently at the specified amounts. The two above cases allow for the analysis to be conducted in two methods analogous to internal pipe flow: i) constant surface heat fluxes or a ii) combined constant surface temperature and constant heat flux boundaries. A control volume of the axial flow and its parameters are shown in Fig. 6 per [26]:

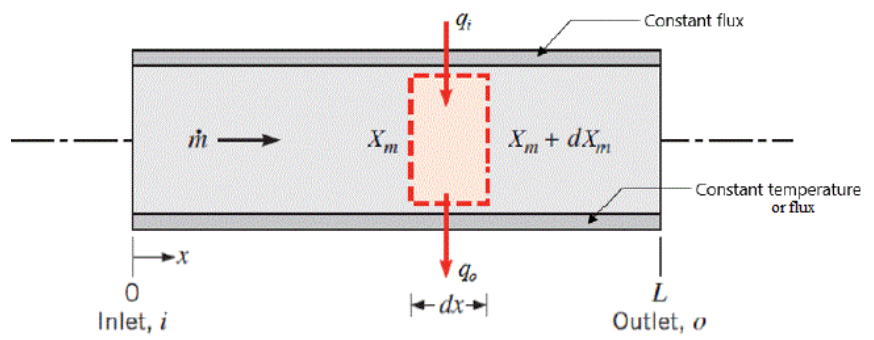

Fig. 6. Axial parameter variation [14].

The following assumptions are made in analyzing the flow via a single chamber of the chimney:

- Fully developed, steady state, and steady flow with neglected entry length effects.
- Flow variations in directions other than axial are neglected.

- Heat input from solar energy is a constant flux through the roof space.

- Heat input from compost is either constant flux or constant surface temperature.

- The chamber sides are well insulated.

- Control volume is taken to be that encapsulating the fluid and does not include the chamber walls.

- Flow is reversible for a baseline entropy model.

- Air is modeled as an ideal gas.

- Height changes are negligible within the flow cavity.

These assumptions essentially quantify the analysis as a bulk fluid property analysis as it progresses axially. Without defining the heat transfer relations the model may be developed by various conservation laws. Conservation of energy yields:

$$
c_{p} \frac{d T}{d x}+V \frac{d V}{d x}=\frac{Q_{\text {irr }}+Q_{\text {compost }}}{\dot{m}}
$$

Balancing the specific entropy, $s$ throughout the differential process yields:

$$
\frac{d s}{d x}=\frac{Q_{i r r}+Q_{\text {compost }}}{\dot{m} T}
$$

Recalling the second Gibb's relation and the ideal gas law and substituting into the entropy relation gives:

$$
c_{p} \frac{d T}{d x}-\frac{1}{\rho} \frac{d p}{d x}=\frac{Q_{i r r}+Q_{\text {compost }}}{\dot{m}}
$$

Recognizing the equivalent results from conversation of energy and entropy generation gives:

$$
V \frac{d V}{d x}=-\frac{1}{\rho} \frac{d p}{d x}
$$

Which should be noted is the same result achieved from an analysis using the Navier-Stokes equations in the axial direction with the assumption of inviscid flow (i.e. we recover Bernoulli's equation). Differentiating the ideal gas law $p$ $=\rho R T$ and mass flow equations affords

$$
\begin{gathered}
\frac{d p}{d x}=R\left(\rho \frac{d T}{d x}+T \frac{d \rho}{d x}\right) \\
\frac{1}{A_{c}} \frac{d A_{c}}{d x}+\frac{1}{V} \frac{d V}{d x}+\frac{1}{\rho} \frac{d \rho}{d x}=0
\end{gathered}
$$

Combining the above relations gives rise to the differential relationship

$$
\left(V-\frac{1}{V}\right) d V+R d T+d \rho\left(\frac{p}{\rho^{2}}-\frac{1}{\rho}\right)=0
$$


Consequently, this may be solved yielding

$$
\frac{1}{2}\left(V^{2}-V_{o}^{2}\right)+R\left(T-T_{o}\right)+\int_{\rho_{o}}^{\rho} \frac{p}{\rho^{2}} d \rho=C
$$

where $C$ is an arbitrary constant of integration. Unfortunately the result of Eqn. (13) cannot be explicitly determined due to the presence of the integral term. However this equation can later be used as an error checking device, comparing the results obtained from neglecting the velocity terms in the conservation equations. Utilizing that approach, we return to the conservation of energy equation and neglect the velocity term yielding

$$
\frac{d T}{d x}=\frac{Q_{i r r}+Q_{\text {compost }}}{\dot{m} c_{p}}
$$

From here, the heat transfer term for irradiance has been previously defined as:

$$
Q_{i r r}=\tau f_{s} G d A=\tau f_{s} G B\left(1-\frac{x}{H}\right) d x
$$

For heat transfer from the compost there are two options as earlier discussed. i) constant surface heat flux, ii) constant surface temperature. The first is constant surface heat flux. Given the value of heat transfer per ton, the differential compost heat transfer rate can then be expressed for a differential element as:

$$
Q_{\text {compost }}=\frac{m_{c} \dot{q}_{c}}{H-R} d x
$$

In the case of a constant surface temperature analysis for the compost, this can be accomplished via convection

$$
Q_{\text {compost }}=h\left(T_{s}-T\right) B\left(1-\frac{x}{H}\right) d x
$$

where the convective heat transfer coefficient can be approximated as an average and based on values for solar chimney analysis found in [27]. In both cases i) and ii) for the above compost heat transfer equations, the differential equation presented can be solved quite easily.

The differential equation for the constant surface heat flux case is given by:

$$
\frac{d T}{d x}=\frac{\tau f_{s} G B(1-x / H)+m_{c} \dot{q}_{c} /(H-R)}{\dot{m} c_{p}}
$$

The solution to this equation gives the temperature distribution for constant heat flux as:

$$
T(x)=T_{i}+\frac{\tau f_{s} G B\left(x-\frac{x^{2}}{2 H}\right)+\frac{m_{c} \dot{q}_{c}}{H-R} x}{\dot{m} c_{p}}
$$

Likewise, the differential equation for constant surface temperature is given by:

$$
\frac{d T}{d x}=\frac{\tau f_{s} G B(1-x / H)+h\left(T_{s}-T\right) B(1-x / H)}{\dot{m} c_{p}}
$$

The solution to this equation gives the temperature distribution for constant surface temperature as:

$$
\begin{aligned}
& T(x)=T_{s}+\frac{\tau f_{s} G}{h}+ \\
& \left(T_{i}-T_{s}-\frac{\tau f_{s} G}{h}\right) \exp \left(-\frac{B h}{\dot{m} c_{p}}\left(x-\frac{x^{2}}{H}\right)\right)
\end{aligned}
$$

Since there are now solutions for the temperature gradient $d T / d x$ within the chamber, the entropy gradient $d s / d x$ can also be determined from the previously developed relations and thus fixing the air state at any point within the chamber. These final results can be checked against the actual solution to determine the deviation of the results from actual. It should be noted that iteration must occur across the variables until inlet guesses and outlet results are converged.

\section{RESULTS}

Several previous studies have presented thermal based analysis which warrants the use of solar chimney as a viable renewable energy technology. Gannon and Backstrom [8] laid the framework of what are now the fundamentals of solar chimney thermodynamic cycle analysis. The work of [6] Chen et al. give a comprehensive thermodynamic analysis of a low-temperature waste heat recovery system based on the concept of solar chimney. Herein, typical parameters are 24 acre plant with 12 chambers ( 10 to be used $24 / 7,2$ to be cycled out for cleaning and maintenance, $66{ }^{\circ} \mathrm{C}$ tower entrance air temperature (maximum temperature that promotes compost effect) $\mathrm{kW} /$ ton of waste heat absorbed by inlet ambient air and $20 \%$ turbine efficiency (including mechanical to electrical losses) Using the results of the theory developed herein for the hybrid compost waste heat/solar energy model are shown in Table I, Table II and Fig. 7, respectively. Table I shows the parameters suggested by COMPO Energy Inc. for the tower sizing along with a test station in Pomona CA so that some sample results can be produced for evaluation.

TABLE I: ANALYSIS PARAMETERS FOR CHAMBER

\begin{tabular}{|l|l|l|}
\hline Parameter & Description & Value \\
\hline$B$ & Entrance Width & $187.45 \mathrm{~m}$ \\
\hline$H$ & Axial Length to Center & $350.52 \mathrm{~m}$ \\
\hline$R$ & Tower Diameter & $7.315 \mathrm{~m}$ \\
\hline$d$ & Pile to Roof Height & $3.048 \mathrm{~m}$ \\
\hline$T_{i}$ & Inlet Temperature & $18.33^{\circ} \mathrm{C}$ \\
\hline$p_{i}$ & Inlet Pressure & $101.3 \mathrm{kPa}$ \\
\hline$G$ & Irradiance & $5.33 \mathrm{kWh} /$ day \\
\hline$\tau$ & Roof Transmissivity & $94 \%$ \\
\hline$f_{s}$ & Shading Factor & $60 \%$ \\
\hline$T_{s}$ & Compost Surface & $49{ }^{\circ} \mathrm{C}$ \\
& Temperature & \\
\hline$m_{c}$ & Mass of Compost & $7.3 \times 10^{6} \mathrm{~kg}$ \\
\hline
\end{tabular}


Using the parameters of Table I in the compost waster heat generation model developed herein, the axial temperature variation can be visualized in the sample. Fig. 7 displays the temperature variation along the solar chimney chamber for the constant heat flux model, and the constant surface temperature model developed herein as Eqn. (19) and Eqn. (21), respectively. The summary in Table II displays the results of the thermal-fluids analysis through the chamber.

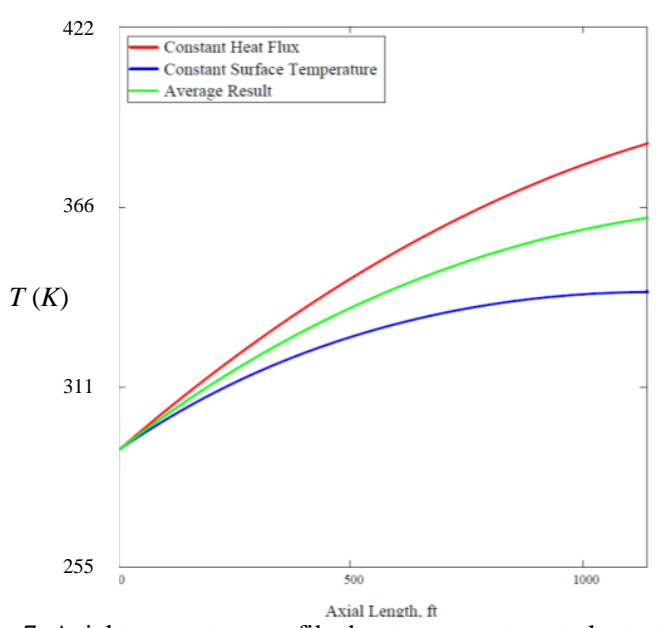

Fig. 7. Axial temperature profile due to compost waste heat addition.

TABLE II: ANALYSIS AVERAGE RESULTS FOR CHAMBER

\begin{tabular}{|l|l|l|}
\hline Parameter & Description & Value \\
\hline$T_{o}$ & Outlet temperature & $90{ }^{\circ} \mathrm{C}$ \\
\hline$p_{o}$ & Outlet Pressure & $101.3 \mathrm{kPa}$ \\
\hline$\rho_{o}$ & Outlet Density & $0.969 \mathrm{~kg} / \mathrm{m}^{3}$ \\
\hline$s$ & Entropy Generated & $218 \mathrm{~J} / \mathrm{kg}-\mathrm{K}$ \\
\hline$h_{o}$ & Outlet Enthalpy & $366 \mathrm{~kJ} / \mathrm{kg}$ \\
\hline$V_{o}$ & Outlet Velocity (Chamber) & $15 \mathrm{~m} / \mathrm{s}$ \\
\hline$V_{\text {tower }}$ & Tower Velocity & $21 \mathrm{~m} / \mathrm{s}$ \\
\hline$Q$ & Total Heat Gain & $6.3 \mathrm{MW}$ \\
\hline$Q_{r}$ & Ratio of Solar to Total Heat Gain & $66 \%$ \\
\hline
\end{tabular}

\section{CONCLUSION}

This paper has also introduced the modeling methodology associated with the concept of using waste heat from composting to increase the air temperature in the inlet chamber of a solar chimney. It is found that from this analysis that the average temperature in the chamber increases as a function of the chamber axial length. For a chimney $1150 \mathrm{ft}$ high and $24 \mathrm{ft}$ in diameter processing 8000 tons of composting material per chamber for a total waste tonnage of a 12 chamber plant being 100,000 tons, the combined total heat gain for this hybrid solar composting chimney is found to be $5930 \mathrm{BTU} / \mathrm{sec}(6.24 \mathrm{MW})$ of which $66 \%(4.12 \mathrm{MW})$ is comprised of solar, and $34 \%$ (2.12 MW) is comprised of composting energy. Thus, this analysis has warranted composting as a viable green energy technology.

\section{ACKNOWLEDGMENT}

The research presented herein was supported by COMPO Energy, Inc.

\section{REFERENCES}

[1] X. Zhou, F. Wang, and R. M. Ochieng, "A review of solar chimney power technology," Renewable and Sustainable Energy Reviews, vol. 14, no.8, pp. 2315-2338, 2010.
[2] J. Schlaich, R. Bergermann, W. Schiel, and G. Weinrebe, "Design of commercial solar updraft tower systems - Utilization of solar induced convective flows for power generation," Journal of Solar Energy Engineering-Transactions of the ASME, vol. 127, no. 11, pp. 117-124, 2005.

[3] M. Al-Dabbas, "The first pilot demonstration: Solar updraft tower power plant in Jordan," International Journal of Sustainable Energy, vol. 31, no. 66, pp. 399-312, 2012

[4] M. Bernardes and X. Zhou, "On the heat storage in solar updraft tower collectors - water bags," Solar Energy, vol. 91, pp. 22-31, 2013.

[5] G. Müller, "Low pressure solar thermal converter," Renewable Energy, vol. 35, no. 1, pp. 318-321, 2010.

[6] K. Chen, J. Wang, Y. Dai, and Y. Liu, "Thermodynamic analysis of a low-temperature waste heat recovery system based on the concept of solar chimney," Energy Conversion and Management, vol. 80, pp. 78-86, 2014.

[7] Compoenergyinc.com. (2015). Compo energy Inc. compo energy beta. [Online]. Available: http://www.compoenergyinc.com/

[8] A. J. Gannon and T. W. von Backstrom, "Solar chimney cycle analysis with system loss and solar collector performance," Journal of Solar Energy Engineering-Transactions of the ASME, vol. 122, no. 3, pp. 133-137, 2000.

[9] M. H. Naraghi and S. Blanchard, "Twenty-four hour simulation of solar chimneys," Energy and Buildings, vol. 94, pp. 218-226, 2015.

[10] H. F. Fasel, L. Meng, E. Shams, and A. Gross, "CFD analysis for solar chimney power plants," Solar Energy, vol. 98, pp. 12-22, 2013.

[11] M. N. Ozturk, "Thermodynamic assessment of an integrated solar power tower and coal gasification system for multi-generation purposes," Energy Conversion and Management, vol. 76, pp. 1061-1072, 2013.

[12] W. W. Li, "A cost-benefit analysis of power generation from commercial reinforced concrete solar chimney power plant," Energy Conversion and Management, vol. 79, pp. 104-113, 2014.

[13] T. Ming, R. K. Richter, F. Meng, Y. Pan, and W. Liu, "Chimney shape numerical study for solar chimney power generating systems," International Journal of Energy Research, vol. 37, no. 4, pp. 310-322, 2013.

[14] A. A. Imran, J. M. Jalil, and S. T. Ahmed, "Induced flow for ventilation and cooling by a solar chimney," Renewable Energy, vol. 78, pp. 236-244, 2015.

[15] A. R. Shahreza and H. Imani, "Experimental and numerical investigation on an innovative solar chimney," Energy Conversion and Management, vol. 95, pp. 446-452, 2015.

[16] P. H. Guo, J. Y. Li, and Y. Wang, "Numerical simulations of solar chimney power plant with radiation model," Renewable Energy, vol. 62, pp. 24-30, 2014.

[17] M. O. Hamdan, "Analysis of solar chimney power plant utilizing chimney discrete model," Renewable Energy, vol. 56, pp. 50-54, 2013

[18] M. Ghalamchi and A. Kasaeian, "Experimental study of geometrical and climate effects on the performance of a small solar chimney," Renewable \& Sustainable Energy Reviews, vol. 43, pp. 425-431, 2015.

[19] H. Jing, Z. Chen, and A. Li, "Experimental study of the prediction of the ventilation flow rate through solar chimney with large gap-to-height ratios," Building and Environment, vol. 89, pp. 150-159, 2015.

[20] R. T. Haug, The Practical Handbook of Compost Engineering, CRC Press, 1993.

[21] Agrilabtech.com. (2014). Agrilab Technologies LLC. [Online]. Available: http://www.agrilabtech.com/

[22] M. Smith and J. Aber, "Heat recovery from compost," BioCycle, vol. 55, no. 2, pp. 26-29, 2014.

[23] A. Koonsrisuk and T. Chitsomboon, "Theoretical turbine power yield in solar chimney power plants," in Proc. 3rd International Conference on Thermal Issues in Emerging Technologies Theory and Applications (ThETA), 2010, pp. 339-346

[24] J. P. Pretorius and D. G. Kroger, "Thermo-economic optimization of a solar chimney power plant," Journal of Solar Energy, vol. 130, no. 2, pp. $15-23,2008$.

[25] NREL. (2015). National Solar Radiation Database. [Online]. Available: http://rredc.nrel.gov/solar/old_data/nsrdb/

[26] F. P. Incropera and D. P. DeWitt, Fundamentals of Heat and Mass Transfer, New Jersey: John Wiley, 2007.

[27] M. A. D. S. Bernardes, T. W. Von Backström, and D. G. Kröger, "Analysis of some available heat transfer coefficients applicable to solar chimney power plant collectors," Solar Energy, vol. 83, no. 2, pp. 264-275, 2009. 


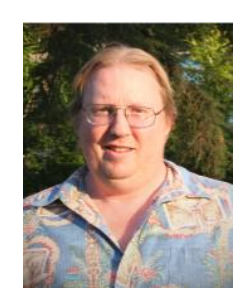

Kevin R. Anderson obtained his BS degree in mechanical engineering at Cal Poly Pomona in 1991, the MS degree in mechanical engineering at the University of Colorado at Boulder, and Ph.D. degree in mechanical engineering at the University of Colorado at Boulder in 1998. He holds a PE license and has over 15 years of practical engineering experience. He is currently a professor of mechanical engineering and the director of the Solar Thermal Alternative Renewable Energy Lab at California State Polytechnic University, Pomona (Cal Poly Pomona). He has a variety of publications in renewable energy, computational fluid dynamics (CFD), and thermal control systems.

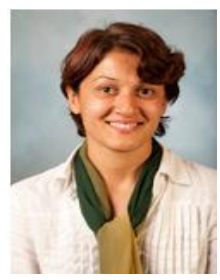

Maryam Shafahi obtained her BS degree at Sahand University of Technology, Iran, in 1999, and received her MS degree at Sistan and Baluchestan University, Iran in 20014 and her Ph.D. degree at University of California Riverside in 2010. She is currently an assistant professor of mechanical engineering at California State Polytechnic University, Pomona $(\mathrm{Cal}$ Poly Pomona). She has a variety of publications in renewable energy, aquaponics, nano-heat pipes, and sustainable energy.

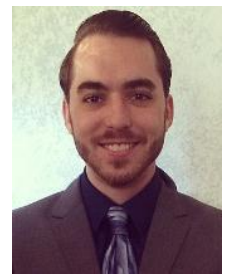

Chris McNamara obtained his BS degree in mechanical engineering at Cal Poly Pomona in 2014 and he is currently working on his MS degree at $\mathrm{Cal}$ Poly Pomona. He is currently a research assistant in the mechanical engineering at California State Polytechnic University, Pomona (Cal Poly Pomona). 